\section{International Scientific Journal Theoretical \& Applied Science}

p-ISSN: 2308-4944 (print) e-ISSN: 2409-0085 (online)

Year: $2018 \quad$ Issue: 02 Volume: 58

Published: $28.02 .2018 \quad$ http://T-Science.org

SECTION 32. Jurisprudence.
Elena Toktonalievna Atamkulova, candidate of juridical science assistant professor of department of theory of law and government of Osh state university of Kyrgyz Republic

Mederbek Payisbekovich Orolbaev, Head of department of criminal procedure of Academy of Ministry of Interrior Affairs of Kyrgyz Republic

Ulanbek Askaralievich Esenov, Head of Researching department of Academy of Ministry of Interrior Affairs of Kyrgyz Republic

Kambarali Avazbekovich Imarkulov, scientist of Researching department of Academy of Ministry of Interrior Affairs of Kyrgyz Republic

\title{
PRELIMINARY LISTENING IN CRIMINAL PROCEDURE OF THE KYRGYZ REPUBLIC: PROBLEMS AND WAYS OF SOLUTION
}

\begin{abstract}
The article discusses some issues of holding a preliminary hearing, in particular, the issues of securing the publicity of the court session. The article justifies the need to ensure the protection of the rights and freedoms of participants in the trial and compliance with the rules of the criminal procedure law. This collision creates many problems that require legislative solutions.

Key words: preliminary hearing, trial, ensuring the procedural rights of the participants in the trial, the general conditions of the trial.

Language: Russian

Citation: Atamkulova ET, Orolbaev MP, Esenov UA, Imarkulov KA (2018) PRELIMINARY LISTENING IN CRIMINAL PROCEDURE OF THE KYRGYZ REPUBLIC: PROBLEMS AND WAYS OF SOLUTION. ISJ Theoretical \& Applied Science, 02 (58): 118-121.

Soi: http://s-o-i.org/1.1/TAS-02-58-25 Doi: crossef https://dx.doi.org/10.15863/TAS.2018.02.58.25

\section{ПРЕДВАРИТЕЛЬНОЕ СЛУШАНИЕ В УГОЛОВНОМ СУДОПРОИЗВОДСТВЕ КЫРГЫЗСКОЙ РЕСПУБЛИКИ: ПРОБЛЕМЫ И ПУТИ РЕШЕНИЯ}

Аннотация: В статье рассмотрены некоторые вопросы проведения предварительного слушания, в частности вопросы обеспечения гласности судебного заседания. $B$ статье обосновывается необходимость обеспечения охраны прав и свобод участников судебного разбирательства и соблюдения норм уголовно-прочессуального законодательства. Данная коллизия порождает множество проблем, требуюших законодательного решения.

Ключевые слова: предварительное слушание, судебное разбирательство, обеспечение прочессуальных прав участников судебного разбирательства, общие условия судебного разбирательства.

\section{Introduction}

В целях реализации указа Президента Кыргызской Республики «О мерах по совершенствованию правосудия в КР» от 8 августа 2012 года №147, решений Совета по судебной реформе при президенте Кыргызской Республики в рамках деятельности экспертной рабочей группы, созданной для разработки законопроектов, направленных на реформирование судоустройств был разработан

новый проект уголовно-процессуального кодекса, который был принят ЖК КР и подписан Президентом КР [1] и будет введен в действие с 1 января 2019 года.

Следует отметить, что новопринятый уголовно-процессуальный кодекс достаточно существенно отличается от ныне действующего, как по содержательной части, так и по структуре. К примеру, нельзя не отметить, появление новых процессуальных институтов, которые
\end{abstract}


отсутствуют в действующем УПК и упразднение уже существующих институтов, в частности упразднение стадии возбуждения уголовного дела.

\section{Materials and Methods}

Новый Уголовно-процессуальный кодекс Кыргызской Республики в качестве нового института закрепил «Предварительное слушание», которое представляет собой самостоятельный этап в судебных стадиях уголовного судопроизводства, а если быть точнее, то является одним из решений судьи, которое принимается до начала судебного разбирательства по поступившему делу, представляя собой усложненную форму судебного заседания.

Предварительное слушание - это разновидность судебного заседания, которое проводится с участием заинтересованных сторон для рассмотрения вопросов, связанных с процедурой последующего судебного разбирательства, а также разрешения вопросов о допустимости и достаточности доказательственной базы по делу.

$$
\text { Общие правила проведения }
$$

предварительного слушания базируются на нормах уголовно-процессуального законодательства, регламентирующих порядок проведения судебного разбирательства.

До сих пор отсутствует единая позиция процессуалистов во взглядах на определение предварительного слушания, которые рассматривают его как особую форму предания суду[2, с.6] ; особый этап уголовного процесса[3, c.7] ; новую самостоятельную стадию уголовного процесса[4, с.22]; ( ряд авторов уточняют, что самостоятельную судебную стадию ) [5, с.58]; особую форму судебного разбирательства по уголовным делам [6, с.51]; как предстадию[7,]; как этап рассмотрения дела по существу[8, с.21] ; особую форму[9, с.7] (процессуальную форму[10, c.99], усложненную форму[11, с.237]; усложненную процессуальную форму[12, с.16]; усложненную дифференцированную форму) стадии подготовки дела к слушанию; форму подготовки дела к судебному разбирательству; самостоятельный институт подготовки и назначения судебного разбирательства; правовой институт уголовного судопроизводства; разновидность судебных заседаний при подготовке дела к рассмотрению в судах первой и второй инстанций; самостоятельную часть судебного разбирательства в суде присяжных; новая форма судебного контроля.

Для проведения предварительного слушания необходимы основания, под которыми следует понимать наличие данных, свидетельствующих об установлении препятствий к рассмотрению дела по существу и достаточность данных, на основе, которых устанавливается наличие признаков таких препятствий

Так, предварительное слушание проводится:

1) по особо тяжким преступлениям;

2) при наличии ходатайства стороны об исключении недопустимых доказательств; Доказательства, полученные с нарушением норм УПК КР, подлежат исключению из числа допустимых доказательств. Однако, следует отметить, что нарушения должны быть существенными.

К существенным можно отнести:

-допрос подозреваемого, обвиняемого без адвоката, тем самым нарушив их право на защиту;

-не ознакомление сторону защиты с постановлением о назначении экспертизы по делу;

-производство досудебного производства лицом, подлежащим отводу;

3) при наличии оснований для приостановления или прекращения дела;

4) при наличии ходатайства стороны о проведении судебного разбирательства в порядке, предусмотренном частью 2 статьи 286 УПК КР; 5) для решения вопроса о рассмотрении уголовного дела судом с участием присяжных заседателей;

6) для решения вопроса о заявленных ходатайствах об изменении меры пресечения, отводах судьи, о приостановлении или прекращении дела.

Ходатайства могут быть заявлены как стороной защиты, так и стороной обвинения. Согласно ст. 276 УПК КР, стороны вправе заявить ходатайство об исключении из перечня доказательств, предъявляемых в судебном разбирательстве, любого доказательства. В случае заявления ходатайства его копия передается другой стороне в день представления ходатайства в суд. Ходатайство о проведении предварительного слушания может быть заявлено стороной в течение 3 суток со дня поступления дела в суд.

Уведомление о вызове сторон в судебное заседание должно быть направлено не менее чем за 3 суток до дня проведения предварительного слушания.

Предварительное слушание должно быть проведено не позднее 10 суток с момента поступления дела в суд.

Таким образом, приходим к выводу, что предварительное слушание представляет собой более усложненную форму подготовки к проведению судебного разбирательства.

Исходя из этого, задачами предварительного слушания выступают: 


\begin{tabular}{|c|c|c|c|c|c|c|}
\hline Impact Factor: & $\begin{array}{l}\text { ISRA (India) } \\
\text { ISI (Dubai, UAE } \\
\text { GIF (Australia) } \\
\text { JIF }\end{array}$ & $\begin{array}{l}=1.344 \\
=0.829 \\
=0.564 \\
=1.500\end{array}$ & $\begin{array}{l}\text { SIS (USA) } \\
\text { PИНЦ (Russia) } \\
\text { ESJI (KZ) } \\
\text { SJIF (Morocco) }\end{array}$ & $\begin{array}{l}=0.912 \\
=0.207 \\
=4.102 \\
=2.031\end{array}$ & $\begin{array}{l}\text { ICV (Poland) } \\
\text { PIF (India) } \\
\text { IBI (India) }\end{array}$ & $\begin{array}{l}=6.630 \\
=1.940 \\
=4.260\end{array}$ \\
\hline
\end{tabular}

-проверка правильности определения подсудности;

-проверка своевременности вручения копии обвинительного акта обвиняемому;

-выяснение вопроса о мере пресечения;

-принятие решений по поступившим ходатайствам и поданным жалобам;

-решение вопросов, связанных с назначением судебного заседания.

Согласно УПК КР, предварительное слушание проводится судьей в закрытом судебном заседании с участием сторон. Однако, уголовно-процессуальное законодательство допускает проведение предварительного слушания без участия лиц, которые не прибыли, но были своевременно извещены. В данном случае возникает вопрос: «не нарушается ли правило судебного разбирательства обеспечение гласности», так как предварительное слушание проводится закрыто, что противоречит концептуальным основам уголовного судопроизводства.

\section{Conclusion}

Общеизвестно, что гласность судебного разбирательства является важнейшим условием судебного разбирательства.

В правовом государстве, обеспечение гласности судебного разбирательства является своего рода «сдерживающим инструментом произвола» со стороны судей и является гарантом законности, справедливости и обоснованности выносимых судом решений.

Присутствие в зале судебного заседания участников судебного разбирательства, представителей средств массовой информации способствует выполнению судом своих обязанностей грамотно и законно.

Но есть и обратная сторона данной проблемы, при открытом судебном заседании может быть разглашена тайна семейного, военного, медицинского, коммерческого характера, которые охраняются Конституцией Кыргызской Республики.
В этом случае, перед законодателем стоит задача нахождения компромиссного варианта между соблюдением условия судебного разбирательства - обеспечение гласности в судебном разбирательстве и охраной тайны, гарантированной Конституцией КР и УПК КР. Решение данной проблемы мы видим в следующем:

1. Предварительное слушание - как форма судебного заседания должна проводиться с соблюдением общих условий судебного разбирательства, то есть гласности судебного разбирательства (ст. 281 УПК КР);

2. Однако, с учетом того, что по УПК КР, предварительное слушание проводится в закрытом судебном заседании, что может повлечь за собой нарушение процессуальных прав участников процесса, необходимо законодательно предусмотреть случаи проведения закрытого судебного заседания, в том числе и предварительного слушания;

3. Так, предварительное слушание должно проводиться в закрытом судебном заседании только:

- по делам о преступлениях против половой неприкосновенности и половой свободы личности и других преступлениях в целях неразглашения сведений об интимных сторонах жизни участвующих в деле лиц либо сведений, унижающих их честь и достоинство;

- в случае рассмотрения уголовных дел о преступлениях, совершенных лицами, не достигшими возраста 16 лет;

-в случаях, когда этого требуют интересы обеспечения безопасности участников процесса, их близких родственников, супруга (супруги);

-в случае, если есть основания полагать, что может быть разглашена военная, государственная, коммерческая, медицинская, коммерческая тайны.

\section{References:}

1. (2018) Available: www.minjust.gov.kg (Accessed: 10.02.2018)

2. Zolotyih V.V. (2009) Deystvie printsipa sostyazatelnosti storonna etape podgotovki $\mathrm{k}$ sudebnomu zasedaniyu $\mathrm{v}$ ugolovnom sudoproizvodstve Rossii: avtoref. Dis k.yu.n. Orenburg, 2009. - p. 6.

3. Morozov A.I. (1998) Sud prisyazhnyih v Rossii i mirovoy opyit.- SPb, 1998. - p. 7.

4. Gavrilov B.Ya. (2005) Sovershenstvovanie dosudebnogo proizvodstva $\mathrm{v}$ svete 


\begin{tabular}{l|lr|ll|ll} 
& ISRA (India) & $=\mathbf{1 . 3 4 4}$ & SIS (USA) & $=\mathbf{0 . 9 1 2}$ & ICV (Poland) & $=\mathbf{6 . 6 3 0}$ \\
Impact Factor: & ISI (Dubai, UAE) $=\mathbf{0 . 8 2 9}$ & PUHL (Russia) $=\mathbf{0 . 2 0 7}$ & PIF (India) & $=\mathbf{1 . 9 4 0}$ \\
& GIF (Australia) & $=\mathbf{0 . 5 6 4}$ & ESJI (KZ) & $=4.102$ & IBI (India) & $=\mathbf{4 . 2 6 0}$ \\
& JIF & $=\mathbf{1 . 5 0 0}$ & SJIF (Morocco) $=\mathbf{2 . 0 3 1}$ & & \\
\hline
\end{tabular}

realizatsiiosnovnyih polozheniy UPK RF//ugolovnyiy protsess- 2005. - \#1. - p.16-22.

5. Zheltobryuhov S. (2005) Soedinenie i vyidelenie ugolovnyih del sudami//ugolovnyiy protsess-2005. - p. 58.

6. Nemyitina M.V. (1995) Rossiyskiy sud prisyazhnyih. Uchebno-metod.posobie. M.,1995. - p. 51.

7. (2018) E.B. Mizulina nazyivaet predvaritelnoe slushanie «predstadiey», otmechaya: «eto ne sovsem stadiya predaniya sudu, k kotoroy myi privyikli, ona suschestvovala $\mathrm{v}$ sovetskom ugolovnom protsesse, eto stadiya imenno stadiya predvaritelnyih slushaniy.

8. Vereschagina M.A. (2007) Institut predvaritelnogo ugolovnomsudoproizvodstve:

Avtoref.dis. Kaliningrad, 2007. - p. 21

9. Kovtun N.N. (2002) Sudebnyiy kontrol v ugolovnom sudoproizvodstve - N. Novgorod 2002- p. 237.

10. Ishimov P.L. (2007) Proizvodstvo predvaritelnogo slushaniya $\mathrm{V}$ sude pervoy instantsii-M., 2007. p. 16.

11. Dudko N.A. (2003) Predvaritelnoe slushanie v sisteme stadiy ugolovnogo protsessa//ugolovnoprotsessualnyie i kriminalisticheskie chteniya na Altae: Materialyi konferentsii. - Barnaul, 2003. Vyip.2. - p. 61.

12. Lupanova S.V. (2006) Predvaritelnoe slushanie kak forma podgotovki delak sudebnomu razbiratelstvu v rossiyskom ugolovnom protsesse: Avtoref.dis.k.yu.n. - N. Novgorod. 